\title{
Abordagem psicanalítica da experiência de adoecimento neurológico: o trabalho de construção na contratransferência
}

Psychoanalytic approach to neurological illness experience: the work of construction on countertransference

Aproximación psicoanalítica a la experiencia con enfermos neurológicos: el trabajo de construcción en la contratransferencia

\section{Perla Klautau* \\ Monah Winograd ${ }^{*}$}

\begin{abstract}
Resumo
A clínica com pacientes neurológicos apresenta especificidades técnicas relativamente aos procedimentos e tipos de intervenção. Em função das perdas cognitivas desses pacientes, um dos trabalhos principais do analista consiste em construir, junto com o paciente, um campo transfero-contratransferencial que privilegie a comunicação afetiva como ferramenta clínica, o que possibilita a atualização de questôes anteriores e permite abordar outras surgidas com e após o adoecimento. Nosso objetivo é investigar a importância do trabalho de construção realizado a partir da contratransferência, características do atendimento desses casos. Para isso, após investigarmos os conceitos de construção e de contratransferência, utilizaremos vinhetas de um caso clínico, a fim de tecer considerações sobre as exigências que esse tipo de clínica demanda da presença do analista durante as sessões.
\end{abstract}

Palavras-chave: Clínica psicanalítica, Adoecimento neurológico, Construções em análise, Contratransferência.

\begin{abstract}
The psychoanalytic treatment of neurological patients presents specific techniques with regard to the procedures and types of intervention. Due to the cognitive impairments of these patients, one of the major tasks of the analyst is to construct, with the patient, a transferencialcountertransferencial field that privileges the affective communication as a clinical tool, allowing the updating of previous questions and the
\end{abstract}

Pós-doutoranda em Psicologia Clínica pela PUC Rio, bolsista FAPERJ, psicanalista, membro efetivo do CPRJ. E-mail: pklautau@uol.com.br.

** Professora do Programa de Pós-graduação em Psicologia Clínica da PUC Rio, psicanalista. E-mail: winograd@uol.com.br. 
addressing of others emerging with and after the illness. Our goal is to investigate the importance of the construction work carried out from the countertransference. To do so, after investigating the concepts of construction and countertransference, we will use parts of a clinical case in order to make considerations about the ways in which the analyst's presence is required in this kind of clinical practice.

Keywords: Psychoanalysis, Neurological patients, Counter transference, Constructions in analysis.

\section{Resumen}

La clínica psicoanalítica con pacientes neurológicos presenta especificidades técnicas relativas a los procedimientos y tipos de intervención. A causa de las pérdidas cognitivas de estos pacientes, una de las principales tareas del analista es construir, con el paciente, un campo transfero-contratransferencial que privilegie la comunicación afectiva como herramienta clínica, lo que permite la actualización de cuestiones anteriores y abordar otras surgidas con y después de la enfermedad. Nuestro objetivo es investigar la importancia del trabajo de construcción realizado a partir de la contratransferência, característica del tratamiento de estos casos. Para ello, después de investigar los conceptos de construcción y de contratransferencia, se utiliza partes de un caso clínico con el propósito de tejer consideraciones acerca de las exigencias que este tipo de clínica pide de la presencia del analista durante las sesiones.

Palabras claves: Clínica psicoanalítica, Pacientes neurológicos, Contratransferencia, Construcciones en análisis.

\section{Introdução}

A clínica com pacientes portadores de lesões cerebrais apresenta 1 especificidades técnicas, sobretudo no que diz respeito aos procedimentos e tipos de intervenção adotados na abordagem psicoterapêutica da experiência de adoecimento neurológico. O principal objetivo deste artigo consiste em investigar a função do analista no tratamento de pacientes neurológicos. Em função das perdas cognitivas, uma das principais tarefas do analista seria a de construir, junto com o paciente, um campo transferocontratransferencial capaz de privilegiar a comunicação afetiva como ferramenta clínica. Da ótica do psicanalista, isso pode ser entendido como um trabalho de construção realizado a partir da contratransferência. Para ilustrar 
esse tipo de trabalho, utilizaremos a descrição de alguns momentos do atendimento de um caso de afasia frontal realizado no âmbito da pesquisa $D o$ cérebro à palavra: a clínica com pacientes neurológicos, aprovada pelo Comitê de Ética da PUC Rio e realizada com o apoio da FAPERJ (Prêmio Jovem Cientista do Nosso Estado - processo n. 101.498/2010).

A primeira etapa da pesquisa clínica consiste no acolhimento dos pacientes adultos portadores de doenças neurológicas e na realização da primeira entrevista, na qual são contemplados: a assinatura do consentimento informado (Resolução do CFP no 016/2000); a identificação da queixa, da demanda de tratamento psicoterapêutico; e o encaminhamento para avaliação neuropsicológica. A segunda etapa comporta a realização de sessões regulares de psicoterapia psicanalítica durante 18 a 24 meses, nas quais são abordados aspectos psicodinâmicos dos sujeitos e testadas variações no enquadre. A terceira etapa consiste na análise dos dados coletados, enriquecidos com elementos fornecidos por avaliações neuropsicológicas. Com base nessa metodologia, foi possível tecer considerações sobre as particularidades técnicas dos atendimentos realizados, já que as exigências desse tipo de clínica diferem em pontos consideravelmente importantes das encontradas na clínica psicanalítica clássica.

Temos observado que, na maioria dos casos, os danos causados pelas lesões cerebrais são experimentados com um sentimento de perda de uma parte de si mesmo (Winograd et al., 2008; Winograd \& Sollero-de-Campos, 2012). Como consequência, no início do tratamento, tal sentimento aparece expresso por um pedido de rememoração, de reconstrução de um passado apagado e anestesiado. Há uma crença de que as lembranças encontram-se perdidas em uma memória inacessível, a qual precisa ser recuperada para restaurar os prejuízos causados pelo esquecimento de nomes, pessoas, lugares e situaçôes que fazem parte de um passado não mais reconhecido como próprio. Esse passado (nos casos em que seja impossível acessá-lo por meio das lembranças) parece de forma impessoal, narrado por alguém cuja proximidade histórica pode não representar uma proximidade afetiva. $\mathrm{O}$ acesso aos fragmentos apagados da memória passa a ser obtido com a ajuda de objetos externos (parentes, amigos, álbuns de fotografias ou documentos, etc.) que, de acordo com Oppenheim-Gluckman (2006), funcionam próteses de memória ou de representação. Ou seja, as referências sobre si mesmo deixam de ser construídas e feitas via rememoração, e passam a ser obtidas por meio do conhecimento de dados referentes à própria história transmitidos por outros. Por isso o material recuperado não é experimentado como pessoal, mas sim como algo artificial: trata-se de um saber externo, não integrado à experiência subjetiva. 
Diante da demanda de reconstrução do passado, cabe ao analista estar ciente de que o trabalho a ser realizado não deve estar pautado na recuperação da lembrança de fatos e eventos que a memória não pode acessar: nesses casos, o material disponível para o trabalho analítico desvia-se do registro da representação. Quando se referem ao passado, os pacientes experimentam sentimentos intensos que trazem consigo a sensação de posse do que foi vivido e fornecem, assim, as coordenadas de que é somente por meio do afeto experimentado que uma via de construção do sentimento de identidade pode ser instaurada. Desse modo, a função do analista consiste em construir, junto com o paciente, um campo transfero-contratransferencial que privilegie a comunicação afetiva como ferramenta clínica. Esse trabalho possibilita a atualização de questôes anteriores ao adoecimento e traz consigo outras a serem investigadas.

Quando o afeto entra em cena, o preocesso comunicativo é ampliado e passa a comportar e conferir destaque à presença sensível do analista na sessão. Isso significa que os processos perceptuais e cognitivos do analista são usados como uma espécie de bússola, a fim de facilitar a compreensão dos afetos comunicados de forma não verbal pelo paciente. Nesse contexto, as noções de construção e de contratransferência são fundamentais para a condução do tratamento de pacientes cuja capacidade de rememoração e de representação encontra-se limitada.

\section{Construções em análise e contratransferência: usos e reformulações}

Tanto o conceito de construção quanto o de contratransferência foram elaborados e pouco usados por Freud. O primeiro só recebeu estatuto de conceito em 1937, no final da vida de Freud; enquanto o segundo foi elaborado entre os anos de 1910 e 1913, no período em que Freud preocupava-se em formar novos analistas. Apesar da distância temporal que marca a formulação dessas duas noções no pensamento freudiano, há uma coincidência no que se refere ao uso e à definição de ambos: tornou-se pouco operativo conservar o sentido restrito que Freud atribui aos dois termos.

Raras são as passagens nas quais Freud menciona o conceito de contratransferência. Em uma delas, no artigo "As perspectivas futuras da terapêutica psicanalítica", Freud (1910) a definiu como uma inovação da técnica relativa ao próprio analista. A ideia era que a contratransferência surgiria como uma influência do paciente sobre os sentimentos inconscientes do médico, ou seja, a contratransferência seria uma reação inconsciente do analista à pessoa do analisando e, particularmente, à transferência deste. 
Contudo, já nesse texto e ao longo de sua obra, Freud foi levado a encarar essa inovação como prejudicial à condução do tratamento analítico, devendo a contratransferência ser identificada, dominada e dissolvida por meio da análise do analista.

Destino diverso teve o conceito de construção, definido como ferramenta clínica alternativa à interpretação. Em 1937, no artigo "Construçôes em análise", Freud comparou o trabalho do analista ao de escavação arqueológica: a tarefa de ambos seria "completar aquilo que foi esquecido a partir dos traços que deixou atrás de si ou, mais corretamente, construí-lo" (Freud, 1990/1937b, p. 293). A ambição de Freud era que o trabalho de construção pudesse ser empreendido pelo analista quando este não tivesse meios de acessar o material recalcado e, portanto, os elementos necessários para a realização do trabalho interpretativo. Para ele, o uso das construções deveria ser feito para apresentar ao analisando um período esquecido de sua história infantil e, com isso, trazer à consciência recordações ou fragmentos de lembranças recalcadas.

De acordo com o que foi exposto, é possível observar que Freud manteve o conceito de contratransferência à parte, em reserva, como um ingrediente que não deveria ser adicionado ao processo analítico. Deveria ser usado pelo analista sim, mas em sua análise pessoal. Já a ideia de construções, apesar de ter sido instrumentalizada como parte da técnica, não teve tempo suficiente para ser desenvolvida: a concepção de construção ficou ligada ao trabalho de remontar lacunas do desenvolvimento infantil com o intuito de obter uma rememoração total dos fragmentos de memórias perdidos. Diante do pouco uso feito por Freud, coube aos analistas pós-freudianos encontrar meios para operacionalizar esses dois conceitos.

Dentre as elaborações efetuadas pelos analistas pós-freudianos, o trabalho de Viderman (1970) pode ser destacado devido ao fato de ampliar a concepção freudiana de que o trabalho de construção seria capaz apenas de remontar à veracidade dos acontecimentos históricos. De acordo com a visada de Viderman (1970), a questão se desloca da construção efetuada pelo analista de fragmentos não acessíveis à memória para a construção de um espaço analítico como parte da cura. Nessa concepção, a construção deixa de ser um trabalho exclusivo do analista e passa a ser feito pela dupla analista-analisando. Com as contribuições de Viderman, o conceito de construção se alargou, englobando dois outros sentidos, além do definido por Freud no artigo "Construções e análise": a) a construção de um campo transfero-contratransferencial; e b) a construção a dois do espaço analítico. 
É importante mencionar que a noção de construção aparecia nos escritos de Freud desde o relato da história clínica do homem dos ratos (1909), embora, como destacou Strachey na apresentação do artigo "Construções em análise", tenha recebido muito menos atenção do que as interpretações nos debates da técnica analítica (Freud, 1990/1918). Por exemplo, no debate em torno da análise do homem dos lobos (um dos casos mais célebres da clínica freudiana), o tema da construção foi muito pouco mencionado, mesmo tendo sido central no caso em questão. Lembremos que toda a história clínica da análise do homem dos lobos (Freud, 1990/1918), girou em torno de uma construção efetuada por Freud em torno da visão da cena primária nos primeiros meses de vida do paciente e do papel desempenhado por essa experiência na compreensão dos sintomas apresentados pelo paciente. Ao longo do tratamento, uma das preocupaçóes centrais de Freud era a de construir ou, digamos, reconstruir pedaços do desenvolvimento infantil não acessível à rememoração. Mas, então, por que somente em 1937 a ideia de construção recebeu o estatuto de conceito na obra de Freud? Nesse ano, Freud também escreveu "Análise terminável e interminável", artigo que pode ser considerado como complementar ao texto "Construções em análise" ou viceversa. Em "Análise terminável e interminável” (Freud, 1990/1937b), é possível observar o pessimismo de Freud em relação ao alcance da eficácia terapêutica da psicanálise como reflexo de seu encontro com casos não analisáveis pelo método clássico. A novidade desse artigo residiu no fato de trazer à tona questôes pouco discutidas até então: casos nos quais a interpretação não funcionou como ferramenta clínica e o recalcamento não era o mecanismo privilegiado de defesa.

Destituído da posição de destaque que ocupava nos casos clássicos de psiconeurose, a pesquisa sobre o recalcamento deu lugar à investigação da clivagem como mecanismo de defesa. Quando a clivagem é operante, a rememoração aparece sob a forma de atos na relação transferencial (Roussillon, 2006), o que pode ser atestado pelo aparecimento de sintomas atípicos, não neuróticos. Um bom exemplo é a alucinação descrita por Freud (1990/1918) no caso do homem dos lobos: a vivência alucinatória do paciente fornecia mais elementos para a realização de um trabalho de construção do que a veracidade histórica à qual Freud tentou obsessiva e insistentemente remontar a partir do relato da visão da cena primária. Pode-se argumentar que a alucinação do homem dos lobos era relativa a experiências subjetivas que foram vividas em uma época primitiva do desenvolvimento infantil, pois, diante do caráter insuportável, a experiência teria sido clivada do eu e deixado uma lacuna que, em uma época posterior do desenvolvimento, teria sido expressa por meio 
de sintomas cuja etiologia não podia ser posta em palavras via rememoração. Como não era de natureza representativa, o que foi clivado retornou em ato, isto é, o material não poderia ser comunicado verbalmente, por isso foi atuado: o paciente fez o analista sentir, perceber, uma parte dele não percebida diretamente por ele mesmo (Roussillon, 2006).

Se examinarmos o texto freudiano de 1937, é possível encontrar elementos que auxiliam o entendimento dessas consideraçôes. Ao descrever o trabalho a ser empreendido com o paciente, Freud fez a seguinte pergunta: "Que tipo de material põe ele à nossa disposição, de que possamos fazer uso para colocá-lo no caminho da recuperação das lembranças perdidas?" (Freud, 1990/1937b, p. 292). E logo deu a resposta:

Todos os tipos de coisas. Fornece-nos fragmentos dessas lembranças em seus sonhos, valiosíssimos em si mesmos, mas, via de regra, seriamente deformados por todos os fatores relacionados à formação de sonhos. Se ele se entrega à associação livre, produz ainda ideias em que podemos descobrir alusões às experiências reprimidas e derivados dos impulsos afetivos recalcados, bem como das reaçôes contra eles. Finalmente, há sugestões de repetições dos afetos pertencentes ao material reprimido que podem ser encontradas em ações desempenhadas pelo paciente, algumas bastante importantes, outras, triviais, tanto dentro quanto fora da situação analítica. Nossa experiência demonstrou que a relação de transferência, que se estabelece com o analista, é especificamente calculada para favorecer o retorno dessas conexões emocionais. É dessa matéria-prima - se assim podemos descrevê-la - que temos de reunir aquilo que estamos à procura (Freud, 1990/1937b, p. 292).

De todo o material enumerado, vale a pena destacar o retorno das "conexôes emocionais" propiciado pela relação transferencial. De acordo com Freud, as conexões emocionais ou, em outros termos, os afetos despertados pela relação transferencial devem ser usados como matéria-prima para as construções. É importante lembrar que os afetos não são apenas despertados no paciente pelas conexôes emocionais restabelecidas na transferência: os afetos também são despertados no analista pela relação contratransferencial. De modo que, levando às últimas consequências o que é proposto no trecho citado, é possível afirmar que os elementos contratransferenciais servem de material para o trabalho de construção (Bertrand, 2008). Tal fato faz da contratransferência um elemento que deve ser adicionado ao material enumerado por Freud, mesmo que ele não tenha feito uso explícito dela como ferramenta clínica. Pelo contrário, em seus escritos, não cansou de alertar os analistas em formação 
sobre o perigo que poderia oferecer ao sucesso do tratamento. Desse modo, coube aos analistas pós-freudianos encontrar meios para operacionalizar esse conceito.

Em "Sobre a contratransferência", Paula Heimann (1960) ampliou o uso dessa noção, apresentando a ideia de que o psicanalista poderia e deveria servir-se da contratransferência na clínica. Para a autora, conforme, durante a sessão, o inconsciente do analista engloba o do paciente, o psicanalista deve usar a contratransferência como um instrumento facilitador da compreensão do inconsciente do analisando. Ainda assim, atualmente não existe um consenso no que diz respeito à definição de contratransferência ou ao seu uso. Pelo contrário, para muitos analistas, a noção de contratransferência ainda é vista como algo que não deve ser acrescido ao tratamento, e sua definição se restringe ao que foi postulado por Freud. Para outros, a ampliação proposta por Paula Heimann serviu para nomear toda e qualquer manifestação do psiquismo do analista durante as sessões. Adotaremos a versão ampliada por Paula Heimann com o intuito de usar as percepções do analista, baseadas na apreensão de conteúdos afetivos, como elementos não verbais pertencentes à sessão. De acordo com essa ótica, esse tipo de material pode ser usado como matéria-prima para o trabalho de construção.

\section{Elementos não verbais: matéria-prima do trabalho de construção}

Para ilustrar o uso de conteúdos afetivos no trabalho de construção realizado a partir da contratransferência, apresentaremos, de forma breve, um caso de afasia frontal. Há mais ou menos dez anos, foi notado um crescimento irregular na região frontal esquerda do cérebro de Amaro. Somente sete anos depois, Amaro procurou o hospital onde foi diagnosticado um tumor ósseo nessa região. Após a retirada do tumor (craniectomia frontal esquerda), Amaro relatou não conseguir lembrar os nomes das coisas nem das pessoas e, além disso, apresentou um quadro de hemiparesia direita que, com o passar dos dias, melhorou espontaneamente. Alguns meses após a cirurgia, o tratamento fonoaudiológico foi iniciado. De acordo com avaliação da equipe, Amaro apresentava desorganização na produção da fala, por meio de dificuldades de iniciativa, programação e planejamento. Demonstrou pouca habilidade na escrita devido ao quadro motor e à dificuldade de organização. Além disso, apresentou dificuldades de solução de problemas abstratos devido à falta de flexibilidade de raciocínio.

Amaro procurou atendimento psicológico por indicação da equipe de Fonoaudiologia que, ao estabelecer a hipótese diagnóstica de afasia frontal, 
detectou um possível quadro de depressão. Esse quadro foi confirmado logo nos primeiros atendimentos. Além de apresentar severas perdas cognitivas decorrentes da cirurgia para retirada do tumor, Amaro vivenciava uma recente perda amorosa. Poucos meses antes da realização da cirurgia, Amaro começou a namorar uma moça que lhe acompanhou durante a sua internação. "Ela ficou comigo o tempo todo, fez coisas por mim que minha mãe nunca fez." Algum tempo depois de sua alta hospitalar, o namoro terminou. Conforme seu próprio diagnóstico, encontrava-se com "o mundo e com o coração partido".

A peculiaridade do caso de Amaro consiste no fato de que, durante os atendimentos psicanalíticos, a experiência de perda amorosa ou, em suas palavras, "de coração partido", serviu como instrumento propulsor para a reestruturação de seu estar no mundo que, como ele dizia, estava rachado, partido, dividido. De acordo com Amaro, em seu mundo partido, era possível localizar o antes e o depois da operação: "Quando saí do hospital tudo mudou, não conseguia me lembrar dos nomes. Eu sabia no pensamento, mas, na hora de achar, de falar, não conseguia”. Isso não acontecia só com nomes, era muito comum na localização de acontecimentos passados.

Antes eu fazia tudo sozinho, não precisava de ninguém para nada. Depois que saí da internação, precisava de ajuda para fazer qualquer coisa. Já melhorei muito, venho aqui sozinho, mas não consigo mais estudar. Eu penso uma coisa, na hora que vou falar não tá mais na minha mente. É a mesma coisa que acontece quando vou escrever.

Ao longo do tratamento, foi possível notar que o mesmo não acontecia quando Amaro falava da falta que sentia da sua namorada. Amaro passou sessóes inteiras chorando e falando da sua dor. Os sentimentos despertados pela experiência do coração partido eram intensos. Inicialmente, nosso trabalho era o de nomear, criar legendas e tonalidades para sentimentos que brotavam durante a sessão: "Para falar dela, as palavras não fogem, nada escapa da minha mente, porque não estão lá, estão dentro do meu coração. Como vou conseguir tirar ela aqui de dentro?”, perguntava Amaro. Essa pergunta, feita incessantemente, sempre acompanhada de uma forte carga afetiva, possibilitou Amaro a iniciar uma (re)construção de seu mundo partido, marcado pela divisão entre o antes e o depois do adoecimento neurológico.

Uma das funçôes do analista no atendimento psicanalítico realizado com pacientes que sofreram lesões cerebrais é o de estabelecer conexões entre lembranças, sentimentos e percepções isoladas. Para tal, é necessário 
que o analista assuma uma postura diferente da comumente adotada no tratamento clássico das neuroses. $\mathrm{O}$ manejo desse tipo de cura é sustentado pela associação livre por parte do analisando, pela atenção flutuante e pela interpretação do material inconsciente recalcado por parte do analista. Quando o que está em pauta é o uso da interpretação como ferramenta clínica, cabe ao analista descortinar o véu que encobre a realidade psíquica, ou seja, os desejos inconscientes recalcados e as fantasias que exercem determinação sobre a formação dos sintomas. Diferentemente das neuroses, o manejo do atendimento de pacientes portadores de lesões cerebrais não opera no domínio da representação e da significação. Como vimos no caso de Amaro, muitas vezes, a lesão cerebral afeta a capacidade perceptiva e representacional. Desse modo, esse tipo de paciente encontra muita dificuldade em acessar as percepções e as representações que construíram sobre si e sobre o seu entorno.

Para acessar o material que precisa ser integrado, torna-se necessário que o analista participe do trabalho associativo usando o próprio funcionamento mental. Isso não significa que o conceito de neutralidade seja abandonado. Pelo contrário, é transformado e ampliado. Mesmo participando do trabalho associativo, o analista mantém a "distância justa" sem se afastar dos fundamentos técnicos (Ferenczi, 2011/1927). Nessas situações, a neutralidade deve ser pensada como uma forma de proximidade neutra. É importante lembrar que tal tipo de proximidade não diz respeito ao compartilhamento de experiências; acontece justamente o oposto: quando o analista se aproxima do material não comunicado verbalmente pelo analisando, o distanciamento em relação aos afetos apreendidos por meio da relação contratransferencial é preservado. Ao se deixar afetar pelas modulações afetivas do paciente, o psicanalista, preservando a neutralidade, passa a participar de forma mais ativa da sessão analítica. Isso significa que a adoção de uma dose de atividade muda a qualidade da presença do analista no processo terapêutico, que passa a incluir todo o seu funcionamento mental, envolvendo mudanças de sensibilidade, de atenção e de percepção. Dessa forma, os processos perceptuais e cognitivos do analista se tornam parte do processo de integração dos sujeitos acometidos por perturbações neurológicas.

Ao longo dos atendimentos, o luto pela perda do objeto de amor foi conferindo um novo modo de estar no mundo para Amaro. Diretamente conectado ao sentimento de perda e a sensação de dor, Amaro encontrava as palavras que escapavam nos momentos em que efetuava tentativas de exprimir seus pensamentos. Em uma das nossas sessões, ao falar de seu sentimento de coração partido, Amaro chorava e dizia: "Meu mundo nunca foi feito de cores com brilho, mas era colorido, agora tudo ficou sem cor, é um cinza que não 
tem fim". Enquanto falava isso, Amaro foi encolhendo-se na poltrona, abraçou os pés e reclinou-se, ficando encolhido e chorando. Amaro estava encolhido na poltrona, como um bebê em posição fetal. Minha sensação era de estar diante de uma criança desamparada. Nesse momento, lembreime de que a mãe de Amaro saía para trabalhar, ficava o dia inteiro fora e o deixava cuidando de seu irmão mais novo. Num dado momento, disse:

Tenho a sensação de que o cinza que não tem fim não começou depois da sua cirurgia nem quando sua namorada terminou a relação de vocês. A impressão que tenho é que esse cinza já existia desde o tempo que sua mãe ficava o dia inteiro fora, quando saía para trabalhar e te deixava cuidando do seu irmãozinho.

Chorando, Amaro me disse: “Também era cinza, minha mãe fazia igualzinho a ela, quando voltava, só cuidava do meu irmão. Ele era pequeno, precisava mais dela, e eu também precisava, mas tinha de cuidar dele". Nessa situação, a construção efetuada encontra-se baseada no contato empático com os conteúdos afetivos despertados pela contratransferência.

Dessa forma, é possível notar que o trabalho associativo é iniciado no momento em que é feita a tentativa de dar um lugar à sensação de estar diante de uma criança desamparada. Para realizar essa construção, é necessário que o psicanalista se identifique e projete no paciente algo proveniente de seu próprio psiquismo. Pelo uso do mecanismo de identificação, é possível estabelecer um contato empático e realizar, de acordo com Kohut (1959), uma "introspecção no lugar do outro".

Ao atingir esse ponto, torna-se necessário estabelecer uma breve e simples diferenciação entre identificação primária, identificação projetiva e empatia. Logo de início, é importante deixar claro que, no uso da empatia, há uma mediação, uma tomada de consciência, uma diferenciação entre eu e não eu que não se encontra presente no processo de identificação primária e tampouco no mecanismo de identificação projetiva. O que faz da empatia um fenômeno diferente da identificação primária, tal como foi descrito por Freud, é o fato de a mediação, entre o que é meu e o que pertence ao outro, ser estabelecida justamente no momento em que um sentimento de identificação se instaura. Deve ficar claro que empatia é um fenômeno que engloba o processo de identificação. É possível enfatizar um elemento do processo de identificação pertencente ao fenômeno da empatia: o sentimento de identificação passageira. Esse deve ser entendido como algo temporário, como uma sensação de comunhão 
com o objeto, seguido do sentimento de separação, capaz de propiciar um distanciamento que permite a demarcação de fronteiras entre o que é meu e o que pertence ao outro.

No artigo "Fantasme et identification dans l'empathie", Beres \& Arlow (2004) lançam a hipótese de que, por meio de uma partilha afetiva, o analista tem acesso aos conteúdos fantasmáticos do analisando. Isso acontece quando o analista se identifica momentaneamente com o seu paciente, despertando um afeto-sinal que o conduz a uma tomada de consciência do tipo: pode ser isso que ele está sentindo. Nesses casos, o afeto-sinal corresponde exatamente ao humor que o paciente provoca no analista. Em outras palavras, o afeto é vivido como sinal que desperta a atenção do analista e anuncia a emergência de um fantasma inconsciente. $\mathrm{O}$ afeto despertado no analista propicia a entrada em contato com as percepções que não foram integradas ao eu. Nesses casos, o afeto funciona como sinal, despertando, no analista, sentimentos provenientes dessas percepções não percebidas e tampouco representadas pelo próprio paciente. Esse afeto-sinal também entra em cena quando o que está em pauta é o mecanismo de identificação projetiva.

$\mathrm{Na}$ identificação projetiva, uma parte cindida do ego é projetada no interior do objeto. A partir do momento em que algo do eu é colocado no outro, o sujeito passa a se relacionar com o objeto externo a partir de sua projeção, atribuindo-lhe características e qualidades provenientes das partes cindidas que foram projetadas sob o objeto. A diferença entre identificação projetiva e empatia está no fato de que, nesta última, o sujeito realiza um movimento de deslocamento, de transposição para dentro do outro, sente dentro do outro, como se fosse o outro, sem se misturar com o outro.

Portanto, diferentemente da identificação projetiva, o processo de empatia se desenrola no terreno pré-consciente, preservando a unidade do eu e reconhecendo a individualidade do outro. Desse modo, não devemos esquecer que, no uso da empatia, o analista estabelece uma mediação, uma tomada de consciência e uma diferenciação em relação ao material que pertence à sua contratransferência e aos afetos comunicados pelo analisando. Portanto, mesmo em situações em que o enquadre analítico clássico (associação livre, escuta flutuante e interpretação do conteúdo recalcado) é rompido, a neutralidade é preservada.

\section{Considerações finais}

Se avançarmos nas considerações suscitadas a partir do atendimento do caso de Amaro, surge a seguinte questão: para que serve o trabalho de 
construção realizado a partir das associações do analista despertadas pela contratransferência? Como vimos, Viderman (1970) aponta um caminho alternativo ao de preencher com fatos históricos as lacunas que ficaram sem memória. Para esse autor, o que está em questão não é a construção de um espaço analítico. Espaço este que possibilita o analista acessar aquilo que para o sujeito assume valor de realidade psíquica e que não pode ser expresso verbalmente por meio de rememoração.

Uma das consequências do posicionamento de Viderman (1970) consiste na ideia de que o inconsciente é construído em análise. Nesse contexto, o trabalho desenvolvido pelo psicanalista Thomas Ogden (1996) merece ser destacado. Ao formular a noção de "terceiro analítico", Ogden amplia a compreensão do processo de identificação projetiva, fazendo, dessa parte, integrante da construção, ou melhor, da criação do campo analítico:

Considero o processo analítico como aquele em que o analisando é criado por meio de um processo intersubjetivo similar àquele presente na identificação projetiva. Uma análise não é simplesmente um método de descoberta do oculto; é principalmente um processo de criação de um sujeito analítico que não existia antes. Por exemplo, a história do analisando não é descoberta, ela é criada na transferência-contratransferência, num fluxo perpétuo em que a intersubjetividade do processo analítico evolui e é interpretada pelo analista e pelo analisando (ver Schafer, 1976, 1978). Desta forma, o sujeito analítico é "criado por", e existe em permanente evolução na intersubjetividade dinâmica do processo analítico: o sujeito da psicanálise toma forma no espaço interpretativo entre analista e analisando (Ogden, 1996, p.41).

Ogden (1996) define a identificação projetiva como uma forma de terceiridade intersubjetiva. Sob a ótica desse autor, o processo de identificação projetiva pode ser conceituado como a criação de uma subjetividade. Para sustentar esse argumento, Ogden apoia-se na teoria de Bion:

A identificação projetiva é considerada um processo em que os pensamentos do bebê que não podem ser pensados e os sentimentos que não podem ser sentidos são evocados na mãe quando esta é capaz de se tornar psicologicamente disponível para ser usada (Ogden, 1996, p. 39). 
Nesse caso, assistimos à criação de uma terceira subjetividade por meio da interpenetração de duas subjetividades: "Nessa relação dialética, projetor e 'recipiente' entram numa relação de at-one-ment e está separado simultâneas" (p. 40). Ao transpor essa dialética para a clínica psicanalítica, Ogden refere-se à "experiência de estar simultaneamente dentro e fora da intersubjetividade do analista-analisando" como "terceiro analítico" (Ogden, 1996, p. 59). Sendo assim, o terceiro analítico deve ser entendido como produto da interpenetração produzida pelas subjetividades do analista e do analisando. Para Ogden, a experiência analítica acontece justamente nessa área terceira que "Ocorre no vértice do passado e do presente e envolve um passado que está sendo recriado (tanto para o analista quanto para o analisando) por meio de uma experiência produzida entre analista e analisando (isto é dentro do terceiro analítico)" (Ogden, 1996, p. 71-72). De acordo com essa lógica, torna-se possível afirmar que a realidade psíquica deve ser entendida como algo a ser construído no espaço analítico e não como algo que deve ser descoberto ou revelado somente pelo acesso ao material inconsciente recalcado.

Para finalizar, é importante ressaltar que não era nosso objetivo realizar uma análise minuciosa do caso discutido nem tampouco apresentar as etapas e os resultados obtidos na pesquisa descrita no início do artigo. O material clínico serviu tão somente para ilustrar algumas das especificidades do papel do analista no atendimento de pacientes neurológicos. Se retornarmos ao trabalho realizado, é possível afirmar que, a partir da construção de um espaço analítico, Amaro foi reconstruindo seu mundo partido. A depressão detectada logo no início do tratamento, isto é, após o adoecimento neurológico e o término do namoro, encobria um quadro depressivo anterior, instalado ainda na infância. A atualização da cena de abandono e o sentimento de desamparo, no início dos atendimentos psicanalíticos, possibilitaram a realização de um trabalho de luto. Trabalho este feito em torno não só dos danos cerebrais e da perda do objeto amado, mas, sobretudo, em torno da condição de menino desamparado: abandonado pelo pai alcoólatra e sempre preterido pela mãe em relação ao irmão caçula.

Com a certeza de que não seria possível "voltar a ser como antes", Amaro encontrou subsídios que o permitiram realizar um trabalho de elaboração das perdas sofridas. Após o processo de reabilitação cognitiva, conseguiu concluir o curso universitário que havia interrompido e trabalhar em sua área. Ao final de nossos atendimentos, Amaro construiu 
novas possibilidades de estar no mundo, descolando-se da posição de menino em busca dos cuidados da mãe. De acordo com suas palavras, agora já era possível "arrumar uma namorada e não uma mãe".

\section{Referências}

Beres, D. \& Arlow, J. A. (2004). Fantasme et identification dans l'empathie. Revue Française de Psychanalyse, 68 (3), 771-790.

Bertrand, M. (2008). Construire um passe, inventer um possible. Revue Française de Psychanalyse, 5, 1359-1417.

Ferenczi, S. (2011). Elasticidade da técnica psicanalítica. In S. Ferenczi. Psicanálise IV. (Obras completas, pp. 29-42). São Paulo: Martins Fontes. (Texto original publicado em 1927)

Freud, S. (1990). Análise terminável e interminável. In S. Freud. Edição standard das obras psicológicas completas de Sigmund Freud (vol. 23, pp. 239288). Rio de Janeiro: Imago. (Trabalho original publicado em 1937a)

Freud, S. (1990). As perspectivas futuras da terapêutica psicanalítica. In S. Freud. Edição standard das obras psicológicas completas de Sigmund Freud (vol. 11, pp. 125-136). Rio de Janeiro: Imago. (Trabalho original publicado em 1910)

Freud, S. (1990). Construções em análise. In S. Freud. Edição standard das obras psicológicas completas de Sigmund Freud (vol. 23, pp. 289-304). Rio de Janeiro: Imago. (Trabalho original publicado em 1937b)

Freud, S. (1990). História de uma neurose infantil. In S. Freud. Edição standard das obras psicológicas completas de Sigmund Freud (vol. 17, pp. 13156). Rio de Janeiro: Imago. (Trabalho original publicado em 1918)

Freud, S. (1990). Notas sobre um caso de neurose obsessiva. In S. Freud. Edição standard das obras psicológicas completas de Sigmund Freud (vol. 10, pp. 157-317). Rio de Janeiro: Imago. (Trabalho original publicado em 1909).

Heimann, P. (1960). Counter-transference. British Journal of Medical Psychology, 33, 9-15. 
Kohut, H. (1959). Introspection, empathy, and psychoanalysis: an examination of the relationship between mode of observation and theory. Journal of American psychoanalytic Association, 7(3), 459-483.

Ogden, T. (1996). Subjects of analysis. London: Karnac Books.

Oppenheim-Gluckman, H. (2006). La pensée naufragée. Clinique psychopathologique des patients cérebro-lésés. Paris: Antropos.

Roussillon, R. (2006). Paradoxos e situaçôes limite da psicanálise. São Leopoldo: Unisinos.

Viderman, S. (1970). La construction de l'espace analytique. Paris: Denoël.

Winograd et al. (2008). Atendimento psicanalítico com pacientes neurológicos. Revista Mal-Estar e Subjetividade, 8(1), 139-170.

Winograd, M. \& Sollero-de-Campos, F. (2012). A experiência subjetiva da lesão cerebral: atopia, identidade e intersubjetividade. In N. Coelho Jr. et al. Dimensões da Intersubjetividade. (pp. 125-145). São Paulo: Escuta. 